\title{
Infrastructure and ecology: 'limited' costs may hide substantial impacts
}

\author{
E. J. Bos ${ }^{1} \&$ J. M. Vleugel ${ }^{2}$ \\ ${ }^{1}$ LEI Wageningen University and Research Centre, The Netherlands \\ ${ }^{2}$ OTB Research Institute, TU Delft, The Netherlands
}

\begin{abstract}
In response to a growing demand for transport and changes in the way people use space, the nature of road infrastructure networks change: (small) roads are frequently transformed into highways. Before such expansions are realized, in many cases a legal obligation exists to carry out a cost-benefit analysis (CBA) in order to assess whether the expansion scheme creates a net social benefit for society. A CBA deals with the effects on the surrounding ecosystem, the environment and human living. This paper focuses on the valuation of the biotic, a-biotic and socio-economic damage, thereby contributing to the methodology of CBA as a tool to evaluate infrastructural plans integrally.
\end{abstract}

Keywords: infrastructure, ecological effects, environmental effects, economic valuation and $C B A$.

\section{Introduction}

Cost-benefit analysis (CBA) has become an important tool to support policy making on public investments in infrastructure. Here we will focus on assessing the external effects of infrastructure in economic terms. More specifically, we will value the ecological and environmental effects of transforming an existing motorway into a highway.

The set-up of the paper is as follows. Section 2 starts with an introduction into CBA. Section 3 continues with an assessment of the ecological, environmental and socio-economic impacts of the highway plan, followed by the economic valuation of these impacts. Then an alternative plan to reroute the highway will be discussed briefly. Section 4 follows with an evaluation of the previous analysis. In section 5 the main conclusions and recommendations can be found. 


\section{Methodology}

Cost Benefit Analysis (CBA) is a well-known tool to support policy makers in making decisions about public investments in infrastructure- and other projects.

In this study, we undertook an extensive review of existing ecological and environmental studies in order to determine the physical impacts of a highway on nature and the environment. This provided a set of parameters. We combined these parameters with data from the plan in order to determine the quantitative impacts of the plan. The translation of these impacts in monetary terms, better known as economic valuation, is the last step to determine the social costs and benefits of the project. It contains uncertain elements, in particular regarding ecological effects [1]. There is also no straightforward, simple and integrative method to value ecological, environmental and socio-economic impacts, instead we combined different valuation methods in the assessment. To some extent this meant navigating at the edge of present knowledge, hence the indicative nature of our final results.

\section{The plan for the highway and its impacts}

\subsection{Introduction}

Kresna Gorge is a small area (17 km in length) located north of the Bulgarian town of Kresna in the southeast part of Bulgaria near the Greek border. Located on the border of the continental and Mediterranean climate zones, the gorge contains a unique ecosystem with a high biodiversity and rare animals and plants: a corridor for mammals and birds.

Nearly $5 \%$, including the most valuable habitats, belongs to the protected Tissata Reserve. The gorge is declared as a CORINE site (Bern Convention) and will become part of the European Ecological Network Emerald and Natura 2000. Part of the gorge is also defined as an important area according to Bird Life
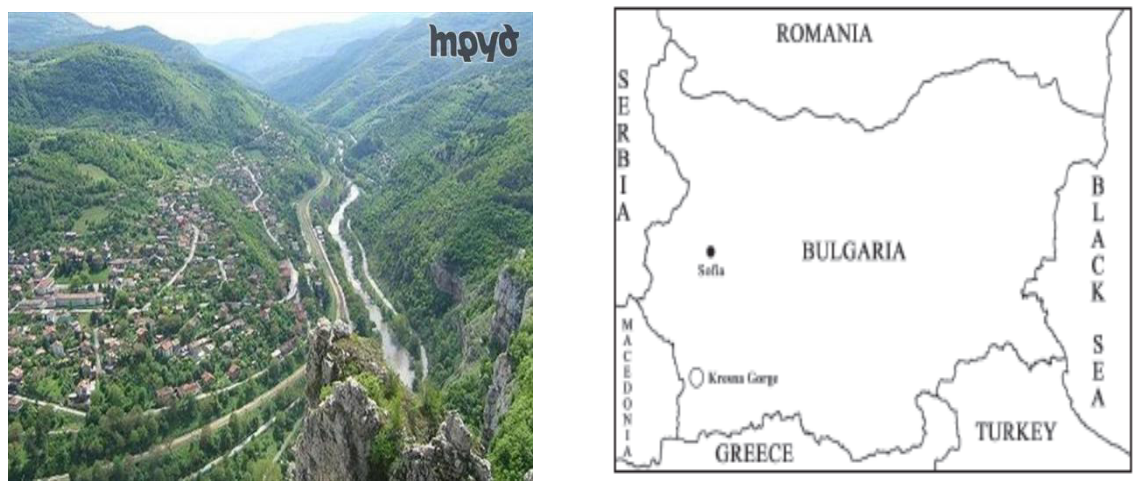

Figure 1: $\quad$ Kresna Gorge in Bulgaria [2, 3]. 
International criteria. Bulgarian environmentalists aim to turn the whole Kresna Gorge into a protected area. It could be linked with FYROM's nature areas as a Transborder Nature Park [4].

\subsection{The existing motorway}

The gorge and Kresna town are divided by the nine meter wide international road between Sofia and Athens (Figure 2). Traffic on this road kills hundreds of animals, such as (rare) snakes, polecats, tortoises, bats and otters, during their daily migration to the Struma River [4, 5].

\subsection{The plan for the highway}

Since 1997, a plan by the Bulgarian government did exist to replace the existing 2x1 lane motorway by a 2x2 lane (plus emergency lanes) E-79 highway. The European Union financially supports infrastructure projects of international importance by its Trans European Network (TEN) policy. The E-79 is part of Priority Project $\mathrm{N}^{\circ} 7$ (Igoumenitsa/Patra-Athina-Sofia-Budapest). An evaluation says [6, p. 18]: "Bulgaria intends to invest a major part of its Cohesion Fund 2007-2013 on the motorway route Sofia-Kulata (the Struma motorway). However, serious environmental constraints could lead to delays on a $56 \mathrm{~km}$ section at the "Kresna Gorge". These 'constraints' refer to the highway dissecting the Kresna Gorge and passing the edges of Kresna town at 30 meters.

\subsection{The physical impact of the highway}

When in use, the highway will produce a range of ecological, environmental and economic effects [4], which will be described here. Besides these external costs, the cost of building the highway is $€ 1.2$ billion [7].

\subsubsection{Ecological (biotic) impact}

The presence of a road alters hydrological dynamics, disrupts natural processes and habitats, but may also create new habitat edges. The assessment was

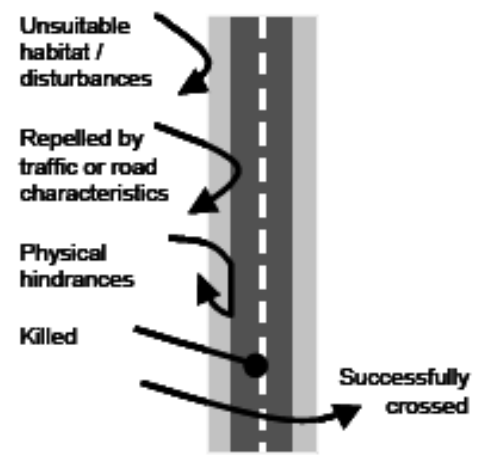

Figure 2: The barrier effect of a road. Source: [8]. 
restricted to fauna. The first impact is the barrier effect. Traffic imposes dispersal and migration range barriers to most non-flying terrestrial animals and causes death while crossing the road [8]. The barrier effect is a combination of disturbance and avoidance effects, physical hindrances and traffic mortality, together reducing the number of movements across the barrier (Figure 2).

The barrier effect is a non-linear function of [10]:

- $\quad$ traffic intensity: from $6.000-8.342$ per 24 hours in the current situation to 17.200 in case the highway would be built;

- $\quad$ average vehicle speed: from 70 to $90 \mathrm{~km} / \mathrm{h}$;

- $\quad$ road width: from 9 to at least $25 \mathrm{~m}$;

- roadside characteristics: more hard elements;

- $\quad$ type of species, behavior, sensitivity to disturbances.

When the traffic intensity would increase if the current road would be replaced by the highway, the road would become an absolute barrier to cross for some animals, as Table 1 shows. In that case the animal species cannot cross the barrier and populations on each side of the road become isolated. When, as a consequence, habitats on each side of the rode become too small (see Figure 3) the specie will become extinct in the area.

Many mammals will not be able to pass the road. Birds are also less likely to fly over the road. We assume an increase of the barrier effect by a few percentages.

Table 1: $\quad$ Barrier-effect of roads: traffic intensity values where roads become absolute barriers to cross.

\begin{tabular}{c|c}
\hline Species & Traffic intensity (vehicles/day) \\
\hline Lizard, viper, reddish vole & 2.000 \\
Northern vole, squirrel & 3.500 \\
Marten, badger, roe-deer, fox & 12.000 \\
Red deer, swine, otter & 15.000 \\
\hline
\end{tabular}

Source: [9].

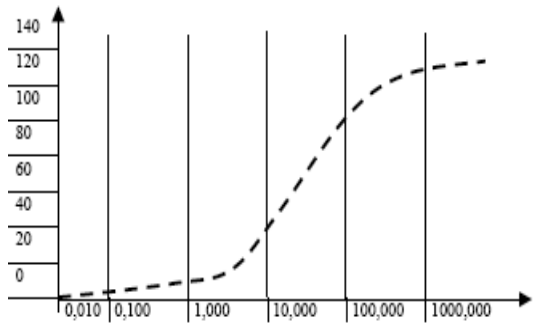

Figure 3: The relation between the number of species and the surface of an area (y: number of species, $\mathrm{x}$ : area in $\mathrm{km}^{2}$ ). Source: [9]. 
Disturbance. When the average vehicle speed increases by $10 \mathrm{~km} / \mathrm{h}$ and the traffic intensity increases as expected, the area affected increases by $44 \mathrm{~m}$ [11]. If we take the change in bird densities as an indication for the increased disturbance of the ecosystem, then the disturbed area will increase by 74.8 ha.

Mortality effect. The number of road kills generally increases with traffic intensity. High mortality will occur among amphibians and mammals, especially bear and wolf. Next to this insects, birds and bats are also affected [8]. We expect an increase by a few percentages.

Habitat loss. The net loss of wildlife habitat would be at least 27,2 ha ([259] $x 17 \mathrm{~km}$ ). If the highway is constructed in the narrow bed of the gorge, most of the current natural habitats along the Struma River will be destroyed.

Artificial lightning. This effect is not easy to quantify, but we assume the spatial burden to be limited to the direct surroundings of the highway.

Depending on the number of successful crossings relative to the size of the population, the barrier effect may affect the populations of species. If the exchange of individuals is further reduced but not completely inhibited, the populations may diverge in characteristics such as density, sex ratio, birth and mortality rate. Also genetic differences may emerge, as the chance for mating with individuals from the other side of the road barrier is reduced. Fragmentation may lead to inbreeding witness studies on rodents and amphibians. A barrier becomes absolute for a species when crossings stop. If isolated areas become too small to live for a certain species, then it becomes extinct in the region [9].

Table 2: $\quad$ Ecological impacts of the highway.

\begin{tabular}{|c|c|c|}
\hline Effects & Variable (\# of) & $\uparrow / \downarrow$ \\
\hline Barrier effect & Unsuccessful crossings & $\pm 5 \% \uparrow$ \\
\hline Disturbance effect & Ecologically disturbed area & 74.8 ha $\uparrow$ \\
\hline Mortality effect & Kills per unit of time & $\pm 5 \% \uparrow$ \\
\hline Habitat loss & Destroyed habitat & $>27.2 \mathrm{ha} \uparrow$ \\
\hline Artificial lightning & Disorientation, fixation & $\uparrow$ \\
\hline
\end{tabular}

While many species will disappear, some may benefit. For instance, road verges can be beneficial to animals and plants, depending on the type of roads. Quiet roads with little traffic are expected to be more beneficial than highways.

\subsubsection{Environmental (a-biotic) impact}

The first effect concerns disruption of natural processes. Quantification of this effect is difficult, however.

Air contamination. Examination of sensitive organisms demonstrates that the current road affects the slopes along the Struma River up to $2 \mathrm{~km}$ away. Higher traffic intensities may be balanced by less congestion. We assume a certain increase in contamination due to the highway.

Adverse effects from construction, maintenance and use of the road. The size of the affected area is likely to increase. 


\subsubsection{Impact on size and nature of recreation}

Several (eco-)activities are under development. A visually less attractive and noisy landscape will attract less visitors. A relatively comparable case is the reactivation of the Dutch section of the Iron Rhine railway [12]. From it we estimate the number of recreational visits to fall by more than 10 per cent.

Table 3: $\quad$ Environmental impacts of the highway.

\begin{tabular}{|c|c|c|}
\hline Effects & Variable (\# of) & $\uparrow / \downarrow$ \\
\hline $\begin{array}{c}\text { Disruption of natural processes (ground } \\
\text { water etc.) }\end{array}$ & & $\uparrow$ \\
\hline Air pollution & $\mathrm{Mg} / \mathrm{ltr}$ air & $\uparrow$ \\
\hline $\begin{array}{c}\text { Adverse effects from construction, } \\
\text { maintenance, use of the road }\end{array}$ & & $\uparrow$ \\
\hline
\end{tabular}

Table 4: $\quad$ Recreational impacts of the highway.

\begin{tabular}{|c|c|c|}
\hline Effects & Variable (\# of) & $\uparrow / \downarrow$ \\
\hline $\begin{array}{c}\text { Less attractive recreational } \\
\text { environment }\end{array}$ & Recreational visits & Region: $\downarrow 10 \%{ }^{1)}$ \\
\cline { 2 - 3 } & & Nation: \pm 0 \\
\hline
\end{tabular}

Note: 1) Very indicative. Eco-tourism will be affected, because the Struma river is a favorite area, as is the large Melo Sand Hill near Kresna town.

Table 5: $\quad$ Socio-economic impact.

\begin{tabular}{|c|c|c|}
\hline Effects & Variable (\# of) & $\uparrow / \downarrow$ \\
\hline Income and wealth & $\begin{array}{c}\text { Decrease of agricultural } \\
\text { land, accessibility }\end{array}$ & $0 / \downarrow^{1)}$ \\
\hline Human health & Pollution of air, soil, water & $\uparrow$ \\
\hline & $\begin{array}{c}\text { Risk for drivers and } \\
\text { trespassers }\end{array}$ & $\uparrow^{2)}$ \\
\hline & $\begin{array}{c}\text { Noise disturbance to } \\
\text { humans }\end{array}$ & \\
\hline
\end{tabular}

Notes:

1) 0 if the road is built in the nature area only, else a decrease. Junctions would improve accessibility, but they are not planned.

2) No secondary road or (level) crossings are planned. Tractors and horse drawn carts are mainly used by farmers. Accidents with larger animals at high speed will be more frequent and more dangerous.

3) The road is very close to the town of Kresna. The value of houses will be reduced. 


\subsubsection{Socio-economic effects}

To be mentioned are the following impacts:

Agriculture. We assume that the highway will be built mainly in the nature area.

Health effects. Exposure to aerosols is accounted for earlier deaths of thousands of people each year [13].

Risk for drivers. Police records in Europe (excl. Russia) suggest at least 0.5 $\mathrm{m}$. ungulate-vehicle collisions per year, or at least 300 human fatalities, 30.000 injuries, and material damage of more than US\$ 1 bn. [8] The gorge inhabits large mammals like bear, wolf and deer.

Noise disturbance. Long term exposure to noise can induce psychological stress and eventually lead to physiological disorder.

\subsection{Economic evaluation}

Ecological and environmental impacts are not revealed by market prices as they concern nonuse values. We used a set of methods best fitting to the purpose.

Barrier effect. Method: avoidance cost. We assume two ecoducts of $60 \mathrm{~m}$ length, $30 \mathrm{~m}$ width and $5 \mathrm{~m}$ height with a cost of $2 \times 1.7$ million [14].

Disturbance effect. Method: avoidance cost. Noise shields cost approximately $€ 60.000$ for a shield of $3 \mathrm{~m}$ high and $150 \mathrm{~m}$ long [15].When applied to the $17 \mathrm{~km} \mathrm{E-79}$ the cost would be $2 *(17.000 / 150) * € 60.000=€ 13.6 \mathrm{~m}$.

Habitat loss. Method: Restoration cost. $€ 272.000$.

Artificial lightning. Method: avoidance cost. Adapting artificial lightning (by limiting direction and amount of light, adaptation to traffic intensity, etc.). Investment cost of approximately $€ 80,000$ per $\mathrm{km}$ of road [15]. When applied to the $17 \mathrm{~km} \mathrm{E}-79$ the total costs would be $80.000 * 17=€ 1.36 \mathrm{~m}$.

Environmental effects. The appropriate method would be CVM. No data were available, hence we used a pro memorie (PM) as proxy.

Impact on recreation (use values). Methods: Market valuation, travel cost. Impact on recreational spending will be negligible if we assume substitution on a national scale. The welfare loss is due to the decreased recreational value of the sites, hence shift of travel to other sites. No data is available, hence a PM.

Socio-economic effects. We assume a negligible impact on agriculture. Human health will be affected. Air pollution could best be valued by hedonic pricing, as no data is available we apply PM. Noise disturbance and risks for drivers are included in the disturbance of the ecosystem.

Total cost: $€ 3.4 \mathrm{~m} .+€ 13.6 \mathrm{~m} .+€ 0.272 \mathrm{~m} .+€ 1.36 \mathrm{~m} .+\mathrm{PM}=>€ 18.7 \mathbf{~ m}$.

\subsection{An alternative}

An alternative route via the Pirin Mountain could prevent all the negative effects. Its impact will be much less than the existing road, which will then be converted into a disclosure route for inhabitants and tourists [5].

EU's environmental regulators can play a vital role in protecting this valuable area against strong economic interests [6]. 


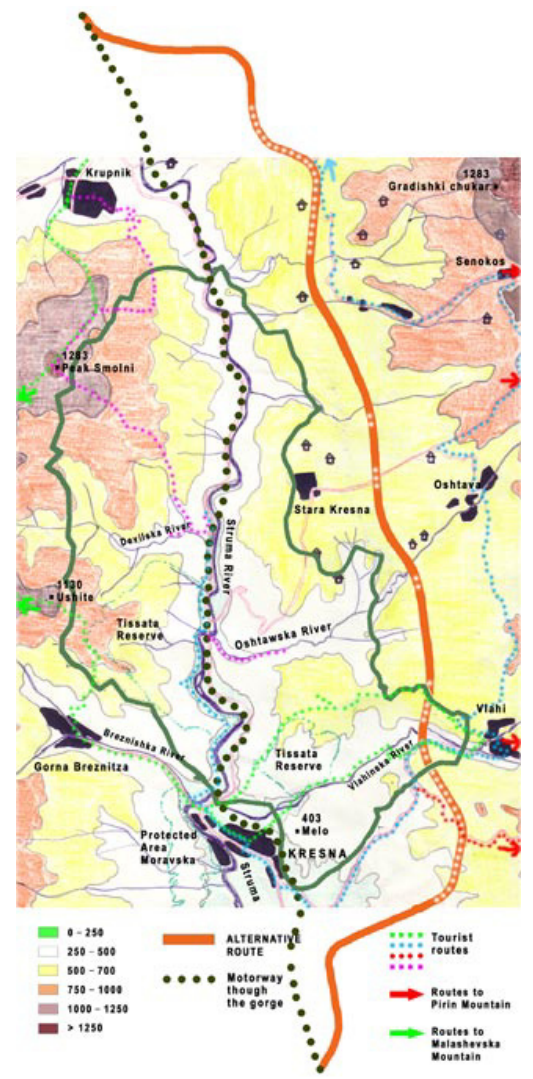

Figure 4: $\quad$ Map of the Kresna Gorge with eastern bypass. Source: [4].

\section{Evaluation}

In this paper we presented the results of a study into the impact of road extension on a rather unique and irreplaceable nature area. The importance of this paper lies in the depth of the ecological analysis and valuation on the one hand and the combination of several valuation methods on the other hand. CBA studies tend to concentrate on issues like noise, air pollution, use of space and socio-economic impact. This study went much further. By combining biotic, a-biotic and socioeconomic impacts it was possible to give a relatively complete overview of the impacts of the highway. This way of analyzing gives clues to interesting areas for further research, in particular into ecological and environmental impacts of infrastructure.

The valuation of the external costs of the highway shows a relatively small value of $€ 18.7 \mathrm{~m}$. This is due to a number of factors:

- valuation problems, which lead to an incomplete dataset (PM);

- the prime use of the cost avoidance method, which is a valuation from a human perspective. 
The impact of the existing road is already considerable. The impact of the highway is therefore attenuated. A more cost-intensive in depth study should be undertaken in the gorge in order to remove the PM's from the cost calculation.

\section{Conclusions and recommendations}

A few methodological observations can be made. First, infrastructure projects in nature areas particularly affect nonuse values. Second, avoidance and restoration costs methods are most useful when valuing adverse ecological effects in economic terms. These methods are not based on consumer preferences (wtp), but on observed market prices. These methods can be used to value effects that have been mitigated elsewhere.

An issue for further research is to focus on effects where avoidance cost based data are not available. For such effects contingent valuation could be applied in order to get an indication of the size of these effects in reference to other costs and benefits. A recommendation for policy making is to include effects on surrounding nature areas into the CBA for infrastructure. From our study it is clear that such effects can no longer be omitted from an integral evaluation.

By building infrastructure in nature areas, we threaten the existence of very unique, complex and irreplaceable ecosystems. Unlike built-up areas, which can 'bounch back' after a road is ready, such ecosystems do not recover after the road is finished. The best advice would therefore be to stay out of such areas wherever possible. This is what nature protection is meant to do. To improve the present situation while taking care of the needs of increased (international) traffic and the economy, this highway should be built elsewhere.

\section{References}

[1] Vleugel, J.M., and E.J. Bos, 2008, Ways to deal with the 'temporary value of cost benefit analyses, in: K. Aravossis, C.A. Brebbia and N. Gomez (eds.), Environmental Economics and Investment Assessment II, Wessex Institute of Technology, Ashurst, UK, pp. 171-180.

[2] Nikolov, S. and S. Spasov, 2005, Frequency, density and numbers of some breeding birds in the south part of Kresna Gorge (SW Bulgaria), Acrocephalus 26 (124), pp. 23-31.

[3] http://www.kresna.org/index_en.php.; /motorway_en.php; /gallery_en.php, /alternative_en.php.

[4] Bos. E.J, 2008, Valuation of Ecological Networks - Case study Kresna Gorge Bulgaria, Alterra and LEI Working Report 1896, Wageningen.

[5] http://www.kresna.org/index_en.php and inked pages on the website.

[6] EU DG TREN, 2008, TEN - T Trans-European Transport Network, Implementation of Priority Projects Progress Report, May 2008, Brussels.

[7] http://en.wikipedia.org/wiki/Struma_motorway.

[8] Seiler, A., 2001, Ecological Effect of Roads: a Review. SLU, Uppsala. 
[9] Pouwels, R., R. Jochem, M.J.S.M. Reijnen, S.R. Hensen and J.G.M. van der Greft, 2002, LARCH voor ruimtelijk ecologische beoordelingen van landschappen, Alterra, rapport 492, Wageningen.

[10] Berthoud, G., 2002, Construction of a Motorway in the Gorge of Kresna Corridor Connection Bulgaria - Greece: Motorway E79: Sofia-Kulata. Report of the on-the-spot appraisal. Standing Committee 22nd meeting Strasbourg, 2-5 December 2002.

[11] Reijnen, M.J.S.M., G. Veenbaas and R. Foppen, 1992, Het voorspellen van het effect van snelverkeer op broedvogelpopulaties. DWW-rapport, Rijkswaterstaat Delft/IBN-DLO, Wageningen.

[12] Konijnenburg, P. van, J. Kortman, J. Jantzen and H. van der Woerd (2001). Effecten van Reactivering van de IJzeren Rijn: Onderzoek naar de Effecten van Reactivering van de IJzeren Rijn op de Functies Recreëren, Wonen en Werken, IVAM, Amsterdam.

[13] Slanina, S. and W. Davis, 2008, "Impact of local air pollution.", in: Encyclopedia of Earth, C.J. Cleveland (ed.), Environmental Information Coalition, National Council for Science and the Environment, Washington, D.C.

[14] Vanya Simenova, personal information from Bulgaria.

[15] Rijkswaterstaat, Dienst Weg- en Waterbouwkunde, 2002. Effecten en kosten van leefbaarheidsmaatregelen, Den Haag. 